Abstracted/indexed in Academic Search Complete, Asia Journals Online, Bangladesh Journals Online, Biological Abstracts, BIOSIS Previews, CAB Abstracts, Current Abstracts, Directory of Open Access Journals, EMBASE/Excerpta Medica, Global Health, Google Scholar, HINARI (WHO), International Pharmaceutical Abstracts, Open J-gate, Science Citation Index Expanded, SCOPUS and Social Sciences Citation Index;

ISSN: $1991-0088$

\title{
Pattern of use of analgesics in a surgical unit
}

\author{
Mohammad Abdullah Al Masud, Syed Ashrafuzzaman and Md. Jalaluddin Iqbal
}

Department of Pharmacology and Therapeutics, Sir Salimullah Medical College and Mitford Hospital, Dhaka, Bangladesh.

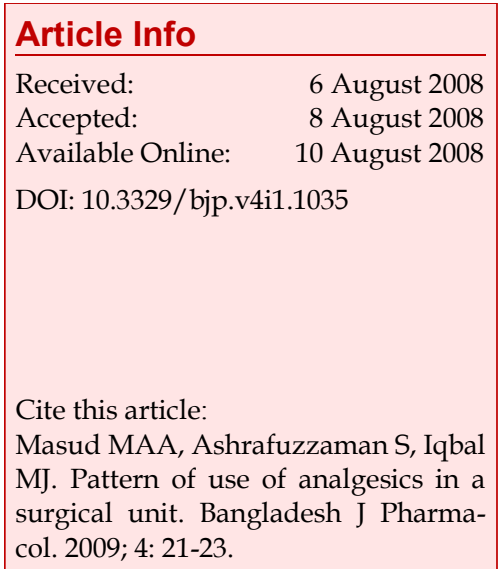

\begin{abstract}
The present study was designed to evaluate the prescribing pattern of analgesics in post-operative patients in a surgical unit. Total number of 180 prescriptions containing analgesics was collected randomly. The only drug in the operation day that was used was pethidine $(90.6 \%)$. Patients $(9.4 \%)$ did not receive any analgesic in the operation day. Associated analgesics in the operation day were either tramadol $(42.2 \%)$ or ketorolac $(54.4 \%)$. Only $3.3 \%$ did not receive any such drugs. In first post-operative day most of the patients received single drug tramadol $(48.3 \%)$, ketorolac $(38.9 \%)$ and pethidine $(0.6 \%)$. In second, third, forth and fifth post-operative day most patients received tramadol $47.8,44.4,41.4$ and $33.2 \%$ respectively. In sixth post-operative day most of the patients $(81.1 \%)$ did not receive any analgesic. In this study tramadol was found to be widely used post-operative analgesic with minimal side effects and better adherence to this drug by the patient.
\end{abstract}

\section{Introduction}

Analgesic used pre-operatively reduces the dose of general anesthetics having low therapeutic index, thereby, producing balanced anesthesia and makes better adherence to the treatment with minimal postoperative complications. Post-operative pain manage ment is an important but seemingly undervalued component of peri-operative care. Over the past decade, medical societies, governmental agencies, and accrediting bodies such as the Joint Commission on Accreditation of Healthcare Organizations (JCAHO) have paid increasing attention to the management of all types of pain, including post-operative pain (Michael, 2006).

Despite this increased focus, the literature suggests that many patients continue to experience significant postoperative pain.

In USA survey of 250 patients who had undergone surgery in the previous 5 years revealed that $82 \%$ reported post-operative pain, and $86 \%$ of those who reported post-operative pain had moderate, severe, or extreme pain (Apfelbaum et al., 2003).

Inadequately controlled pain can cause post-operative morbidity, prolong recovery time, delay return to normal living, and decrease satisfaction with care. Inadequate pain management increases the use of health care resources, thereby increasing total health care costs (Joshi and Ogunnaike, 2005).

Opioid analgesics have long been shown to produce a dose-dependent reduction in the minimum alveolar anesthetic concentration (MAC) of volatile anesthetics (Hoffman and DiFazio, 1970). However, in animal studies designed to assess the effect of ketorolac on the volatile anesthetic requirement, no reduction in MAC could be demonstrated (Rich et al., 1992). Thus, it is not surprising to find that intra-operative anesthetic conditions are generally less satisfactory when ketorolac is used as an alternative to a potent opioid analgesic (Ding and White, 1992).

Despite the failure of NSAIDs to replace opioid analgesics in the management of acute intra- and post- 


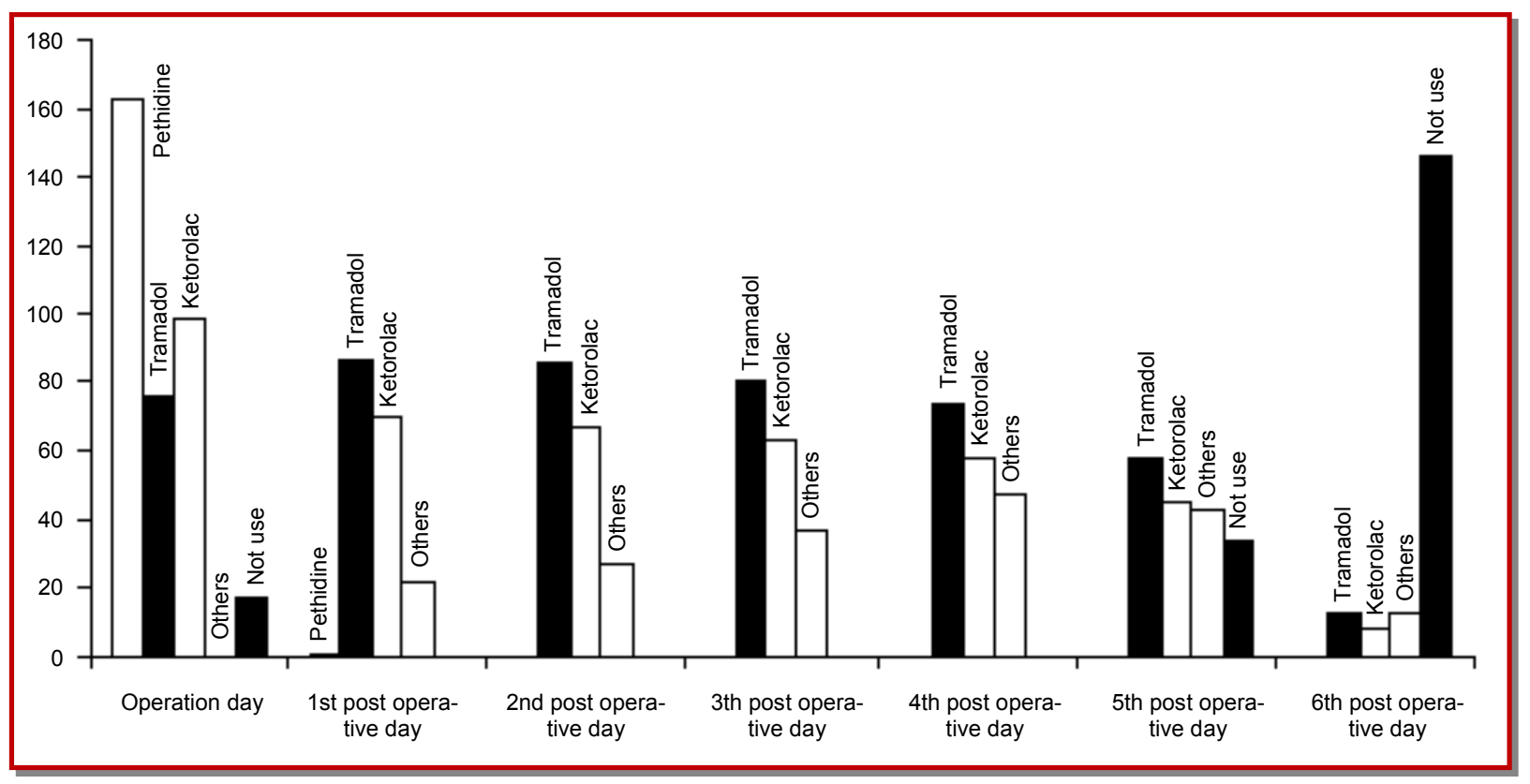

Figure 1: Distribution of the patients admitted in the hospital according to analgesics used from operation day to sixth postoperative day

operative pain, these drugs may play a useful role as adjuvant for improving post-operative analgesia. For example, in a placebo-controlled study involving ambulatory surgery patients, ketorolac, 30/60 mg IV, given intra-operatively, produced a dose-dependent decrease in post-operative pain scores and opioid analgesic requirements (Souter et al., 1994). Postoperative pain is one of the most prevalent types of acute pain and is an expected result of surgical procedures experienced by thousands of patients all over the world (Ashburn and Ready, 2001).

Post-operative pain manifests in a moderate or intense manner in 40 to $60 \%$ of cases for more than $50 \%$ of the time (McCaffery and Ferrell, 1999). Its somatic and psychic expression may be directly or indirectly associated with increased morbidity and mortality, with consequent social and economic repercussions. Thus, over the last decades this organic manifestation has gained the dimensions of a world public health problem (Secoli et al., 2006). In developed countries, the interest in the economic aspects of analgesia applied during the post-operative period is recent and has been concentrated on high-cost treatments, especially in view of the use of new technologies in the management of discomfort (Choinière et al., 1998).

In view of the above considerations and of a scenario in which the practice and the technical decisions of health professionals are increasingly tied to economic restrictions, the present study was designed to evaluate the prescribing pattern of analgesic and see the pattern in a government medical college hospital.

\section{Materials and Methods}

This prospective observational study was carried on 180 patients in a surgical unit from July 2007 to June 2008.

\section{Selection of sample}

The prescriptions given by the medical officers and specialist doctors to the patients undergoing surgery were included in the study. The prescriptions which did not contain analgesics were excluded and the prescriptions of the patients suffering from diabetes mellitus, hypertension and any cardiac diseases were also excluded.

\section{Statistical analysis}

Analysis of data were done with the help of computer by SPSS program version of 12.0 Software facilities.

\section{Results}

Total number of 180 prescriptions containing analgesics was collected randomly. The distribution of the patients admitted in the hospital according to analgesics used in the operation day were as follows- most patients $(90.6 \%)$ in the hospital received pethidine as analgesics in the operation day. Associated analgesics used with pethidine in the operation day were ketorolac (54.4\%). In first post-operative day most patients (48.3\%) received tramadol. In second post-operative day most patients $(47.8 \%)$ received tramadol. In third post- 
operative day most patients $(44.4 \%)$ received tramadol. In fourth post-operative day most patients (41.4\%) received tramadol. In fifth post-operative day most patients $(32.2 \%)$ received tramadol. In sixth postoperative day most patients $(81.1 \%)$ did not receive any analgesics

\section{Discussion}

Diseases for which surgery had been done were cellulitis, cholelithiasis, intestinal obstruction and appendicitis in the hospital. The only drug in the operation day that was used was pethidine. The cause of only use of pethidine was that the drug was supplied by the government. Associated analgesic in the operation day in the hospital was both tramadol and ketorolac. Serdar et al. (2008) conclude that pethidine and tramadol are effective in providing analgesia in pediatric patients. Changes in blood pressure, heart rate and arterial oxygen saturation were minimal and were similar in both drugs.

Despite the failure of NSAIDs to replace opioid analgesics in the management of acute intra- and postoperative pain, these drugs may play an useful role as adjuvant for improving post-operative analgesia. For example, in a placebo-controlled study involving ambulatory surgery patients, ketorolac, 30/60 mg IV given intra-operatively produced a dose-dependent decrease in post-operative pain scores and opioid analgesic requirements (Souter et al., 1994).

Pethidine was used in mostly first post-operative day and occasionally second post-operative day and tramadol was used in later post-operative days. This is due to the better adherence to tramadol by the patients due to its minimal side effects such as cardio respiratory depression with minimal addiction liability as compared to pethidine. Moreover tramadol is widely available and cheaper than pethidine and tramadol is also available in oral form.

Each hospital should have its own need based hospital formulary so that working doctor will strictly adhere to it and prescribe rationally all drugs including analgesics thereby improving the health care delivery system with minimal cost and adverse effects.

\section{References}

Apfelbaum JL, Chen C, Mehta SS, Gan TJ. Post-operative pain experience: Results from a national survey suggest postoperative pain continues to be undermanaged. Anesth Analg. 2003; 97: 534-40.

Ashburn MA, Ready LB. Post-operative pain. In: Bonica's Management of pain. Loeser JD, Butler S, Chapman CR, Turk DC (eds). Philadelphia, Lippincott Williams \& Wilkins, 2001, pp 765-79.

Choinière M, Rittenhouse BE, Perreault S, Chartrand D, Rousseau P, Smith B et al. Efficacy and costs of patientcontrolled analgesia versus regularly administered intramuscular opioid therapy. Anesthesiology 1998; 89: 1377-88.

Ding Y, White PF. Simplified quality of anaesthesia scoring system. Anaesthesia 1992; 47: 906-07.

Hoffman JC, DiFazio CA. The anesthesia sparing effect of pentazocine, meperidine and morphine. Arch Int Pharmacodyn Ther. 1970; 18: 261-68.

Joshi PG, Ogunnaike BO. Consequences of inadequate postoperative pain relief and chronic persistent post-operative pain. Anesthesiol Clin North Am. 2005; 23: 21-36.

McCaffery M, Ferrell BR. Nurse's knowledge of pain assessment and management: How much progress have we made? J Pain Symptom Manag. 1999; 14: 175-88.

Michael RR. Optimizing post-operative pain management. Cleveland Clinic J Med. 2006; 73: s72-76.

Rich GF, Schacterle R, Moscicki JC, DiFazio CA. Ketorolac does not decrease the MAC of halothane or depress ventilation in rats. Anesth Analg. 1992; 75: 99-102.

Secoli SR, Padilha KG, Litvoc J, Peniche ACG. Dor pósoperatória: O custo da terapia analgésica. Rev SOBECC. 2006; 11: 39-44.

Serdar E, Birgul Y, Huseyin I, Baran T. A comparison of analgesic efficacy of tramadol and pethidine for management of postoperative pain in children: A randomized, controlled study. Pediatric Sur Int. 2008; 24: 695-98.

Souter AJ, Fredman B, White PF. Controversies in the perioperative use of non-steroidal anti-inflammatory drugs. Anesth Analg. 1994; 79: 78-90.

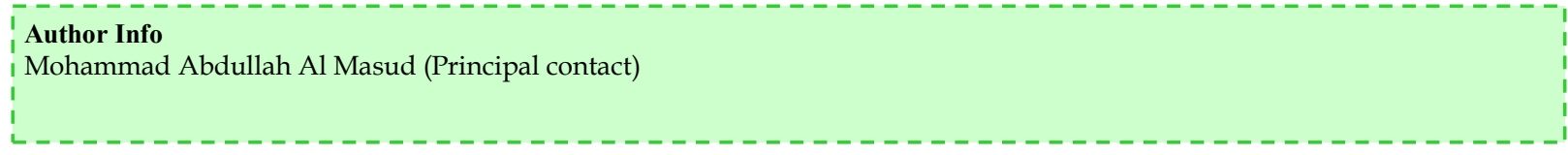

